\title{
Prognostic value of the nutritional risk index in heart transplant recipients
}

\author{
Valor pronóstico del índice de riesgo nutricional en \\ receptores de trasplante cardiaco
}

\author{
Eduardo Barge-Caballero, ${ }^{\text {a,b }}$, Fernando García-López, \\ Raquel Marzoa-Rivas, ${ }^{\mathrm{a}, \mathrm{b}}$ Gonzalo Barge-Caballero, ${ }^{\mathrm{a}, \mathrm{b}}$ David \\ Couto-Mallón, ${ }^{\mathrm{a}, \mathrm{b}}$ María J. Paniagua-Martín, ${ }^{\mathrm{a}, \mathrm{b}}$ Miguel Solla- \\ Buceta, ${ }^{\text {b,c }}$ Carlos Velasco-Sierra, ${ }^{\text {b,d }}$ Francisco Pita- \\ Gutiérrez, ${ }^{\text {bee }}$ José M. Herrera-Noreña, ${ }^{\text {bd }}$ José J. Cuenca- \\ Castillo, ${ }^{\text {b,d }}$ José Manuel Vázquez-Rodríguez, ${ }^{\text {a,b }}$ and María G. \\ Crespo-Leiro ${ }^{\mathrm{a}, \mathrm{b}}$
}

\author{
${ }^{a}$ Servicio de Cardiología, Complejo Hospitalario Universitario de A Coruña, A \\ Coruña, Spain \\ ${ }^{b}$ Instituto de Investigación Biomédica, A Coruña, Spain \\ ${ }^{c}$ Servicio de Medicina Intensiva, Complejo Hospitalario Universitario de A \\ Coruña, A Coruña, Spain \\ ${ }^{d}$ Servicio de Cirugía Cardiaca, Complejo Hospitalario Universitario de A \\ Coruña, A Coruña, Spain \\ ${ }^{e}$ Servicio de Endocrinología y Nutrición, Complejo Hospitalario Universitario de \\ A Coruña, A Coruña, Spain
}

\begin{abstract}
Introduction and objectives. To study the prognostic impact of preoperative nutritional status, as assessed through the nutritional risk index (NRI), on postoperative outcomes after heart transplantation (HT).

Methods. We conducted a retrospective, single-center study of 574 patients who underwent HT from 1991 to 2014. Preoperative NRI was calculated as $1.519 \times$ serum albumin $(\mathrm{g} / \mathrm{L})+41.7 \times$ (body weight $[\mathrm{kg}] /$ ideal body weight $[\mathrm{kg}])$. The association between preoperative NRI and postoperative outcomes was analyzed by means of multivariable logistic regression and multivariable Cox regression. Results. Mean NRI before HT was $100.9 \pm 9.9$. According to this parameter, the prevalence of severe nutritional risk (NRI $<83.5$ ), moderate nutritional risk ( 83.5 $\leq \mathrm{NRI}<97.5)$, and mild nutritional risk $(97.5 \leq \mathrm{NRI}<100)$ was $5 \%, 22 \%$, and $10 \%$, respectively. One year post-transplant mortality rates in these 4 categories were $18.2 \%, 25.3 \%, 7.9 \%$ and $10.2 \%(P<.001)$, respectively. The NRI was independently associated with a lower risk of postoperative infection (adjusted OR, $0.97 ; 95 \% \mathrm{CI}, 0.95-1.00 ; P=.027)$ and prolonged postoperative ventilator support (adjusted OR, 0.96; 95\%CI, 0.94-0.98; $P=.001$ ). Patients at moderate or severe nutritional risk had significantly higher 1 -year post-HT mortality (adjusted HR, 1.55; 95\%CI, 1.22-1.97; $P<.001$ ).

Conclusions. Malnourished patients have a higher risk of postoperative complications and mortality after HT. Preoperative NRI determination may help to identify HT candidates who might benefit from nutritional intervention.
\end{abstract}

\section{Resumen}


Introducción y objetivos. Analizar el impacto del estado nutricional preoperatorio, evaluado mediante el índice de riesgo nutricional (IRN), en el pronóstico tras el trasplante cardiaco (TxC).

Métodos. Se realizó un estudio retrospectivo de 574 pacientes que recibieron un TxC entre 1991 y 2014 en un centro. El IRN preoperatorio se calculó como 1,519 $\times$ albúmina $(\mathrm{g} / \mathrm{l})+41,7 \times($ peso real $[\mathrm{kg}] /$ peso ideal $[\mathrm{kg}])$. La asociación entre IRN preoperatorio y eventos clínicos posoperatorios se analizó mediante modelos multivariables de regresión logística y regresión de Cox.

Resultados. El IRN preoperatorio medio de la población del estudio era de 100,9 $\pm 9,9$. Según este parámetro, las prevalencias de riesgo nutricional grave (IRN $<83,5)$, moderado $(83,5 \leq \operatorname{IRN}<97,5)$ y leve $(97,5 \leq \operatorname{IRN}<100)$ antes del TxC eran el 5, el 22 y el $10 \%$ respectivamente. Las tasas de mortalidad a 1 año tras el TxC en estas 4 categorías fueron del 18,2, el 25,3, el 7,9 y el 10,2\% (p<0,001) respectivamente. El IRN preoperatorio resultó predictor independiente de menor riesgo de infección posoperatoria (odds ratio ajustada [ORa] $=0,97$; intervalo de confianza del 95\% [IC95\%], 0,95-1,00; $p=0,027)$ y ventilación mecánica prolongada posoperatoria (ORa $=0,96 ;$ IC95\%, 0,94-0,98; $\mathrm{p}=0,001)$. Los pacientes con riesgo nutricional moderado a grave mostraron mayor mortalidad a 1 año tras el TxC (hazard ratio ajustada = 1,55; IC95\%, 1,22-1,97; $\mathrm{p}<0,001$ ).

Conclusiones. Los pacientes desnutridos tienen mayor riesgo de complicaciones posoperatorias y muerte tras el TxC. La determinación del IRN podría facilitar la identificación de candidatos a TxC que se beneficien de intervenciones nutricionales en espera del órgano.

\section{Keywords}

Nutritional risk index; Heart transplant; Malnourishment; Outcomes

\section{Palabras clave}

Índice de riesgo nutricional; Trasplante cardiaco; Desnutrición; Pronóstico

\section{Abbreviations}

HF, heart failure; HT, heart transplantation; NRI, nutritional risk index; OR, odds ratio

\section{INTRODUCTION}

Malnutrition is a common comorbidity in patients with heart failure (HF) and is associated with a poor prognosis. ${ }^{1}$ Two classic markers of malnutrition (low body mass index ${ }^{2}$ and hypoalbuminaemia ${ }^{3}$ ) are correlated with increased mortality in this patient population. However, neither of these 2 parameters on its own is a reliable indicator of the nutritional status of patients with HF, as either one can be significantly altered as a consequence of the disease. Serum albumin concentration can be affected by conditions inherent to HF, such as chronic inflammation, fluid overload, hepatic congestion, and renal losses, ${ }^{3}$ while blood volume changes can significantly affect body mass index. ${ }^{4}$ Therefore, nutritional assessment of patients with HF requires alternative clinical tools that are not subject to such variability.

The nutritional risk index (NRI) is a nutritional evaluation score that has become popular in recent years, thanks to its simplicity and strong prognostic value in different medical and surgical patient populations. Buzby et al. ${ }^{5}$ originally defined NRI using the formula $1.519 \times$ serum albumin $(\mathrm{g} / \mathrm{L})+41.7 \times$ (current body weight $[\mathrm{kg}] /$ usual body weight $[\mathrm{kg}])$. It was later suggested to replace the term usual body weight with ideal body weight, ${ }^{6}$ to avoid the difficulty involved in estimating the usual body weight of some individuals, such as the elderly or those with an unstable fluid balance. The ideal body weight, in contrast, can be 
easily calculated using simple anthropometric equations. In both the original definition and the modified formula, NRI has been validated as an independent predictor of mortality and adverse clinical events in a wide range of patients with $\mathrm{HF}$, both chronic ${ }^{7,8}$ and acute, ${ }^{9,10}$ with reduced $^{7}$ or preserved ${ }^{8}$ ejection fraction, as well as in those with advanced disease. ${ }^{10}$

Malnourished patients undergoing cardiac surgical procedures are at increased risk of postoperative complications. ${ }^{11}$ In heart transplant (HT) recipients, as is the case in the general HF patient population, low body weight $^{12}$ and hypoalbuminaemia ${ }^{13}$ are associated with increased mortality risk. However, until now, the potential usefulness of other markers of nutritional risk in this specific clinical context has not been established.

We sought to analyze the prognostic value of preoperative NRI in patients with advanced HF receiving a HT. 


\section{METHODS}

\section{Patients}

This was a retrospective cohort study of patients older than 18 years who had received an orthotopic HT in our center from April 1991, when the program started, until December 2014. The study data were taken from a local database and supplemented with review of clinical records. The A Coruña-Ferrol Clinical Research Ethics Committee approved the study (Consellería de Sanidade, Xunta de Galicia).

The analysis included only patients for whom the pretransplant NRI could be calculated. This parameter was determined using the modified formula where $\mathrm{NRI}=1.519 \times$ serum albumin $(\mathrm{g} / \mathrm{L})+41.7 \times($ actual body weight $[\mathrm{kg}] /$ ideal body weight $[\mathrm{kg}])$. Ideal body weight was calculated using the Lorenz formulae, ie height $(\mathrm{cm})-100-([$ height $(\mathrm{cm})-150]$ / 4) for men and height $(\mathrm{cm})-100-([$ height $(\mathrm{cm})-150] / 2.5)$ for women. As in previous publications, ${ }^{7,9}$ when the value of (actual body weight $[\mathrm{kg}] /$ ideal body weight $[\mathrm{kg}]$ ) was $\geq 1$, NRI was set at 1 . The serum albumin levels and actual body weight used for the preoperative NRI calculation were the closest available to the date of HT in each patient's medical records.

The study patients were classified into 4 nutritional risk categories according to their preoperative NRI, as defined in previous studies ${ }^{7,9}$ : severe nutritional risk (NRI < 83.5), moderate nutritional risk $(83.5 \leq$ NRI < 97.5), mild nutritional risk $(95.7 \leq \mathrm{NRI}<100)$ and no nutritional risk (NRI $\geq 100$ ). We compared the baseline clinical characteristics, incidence of adverse clinical events, and post-HT survival of these 4 patient categories.

\section{Postoperative Clinical Events}

Primary graft dysfunction was defined as isolated right ventricular failure or moderate or severe left ventricular failure of the cardiac graft during the first 24 hours post-HT, in line with the consensus criteria of the International Society for Heart and Lung Transplantation. ${ }^{14}$ Cardiac surgical reintervention was defined as any cardiac surgical intervention requiring a repeat sternotomy during the post-HT hospital stay. Postoperative infection was defined as any infection proven by a microbiological isolate and requiring intravenous antibiotic treatment during the post-HT hospital stay. Prolonged mechanical ventilation was defined as invasive mechanical ventilatory support lasting longer than 36 hours after HT. Acute rejection was defined as any episode of biopsyproven grade $2 \mathrm{R}$ or above acute cellular rejection, ${ }^{15}$ any episode of biopsy-proven grade 1 or above antibody-mediated rejection with associated cardiac graft dysfunction, ${ }^{16}$ or any episode of clinically suspected acute rejection not proven on biopsy that was treated with intravenous bolus steroids, anti-thymocyte globulin, or polyclonal gamma globulin during the post-HT hospital stay.

Information was available on the vital status of all patients at 1 year post-HT. All-cause mortality during this period was the primary event in this study. 


\section{Statistical Analysis}

In this article, continuous variables are presented as-mean \pm standard deviation or median [interquartile range], depending on the normality of their distribution, while categorical variables are presented as percentages. The baseline characteristics of the different NRI categories were compared using the chi-square test for linear trend for categorical variables and ANOVA with a first-order polynomial contrast for continuous variables.

The Cox proportional hazards model was used to identify independent predictors of mortality during the first year post-HT. First, the preoperative variables that showed a statistically significant association with mortality $(P<.05)$ were selected. These variables were included in a backward stepwise analysis (exit criterion, $P>.05$ ) such that the remaining variables (among which was NRI) formed the final multivariable model. To control for potential confounders, the statistical effect of preoperative NRI on post-HT mortality was adjusted using a second extended multivariable model. We forced into this model those variables that showed a significantly asymmetrical distribution over the 4 nutritional risk categories (body mass index, bilirubin, mechanical ventilation, inotropic support, and ischemia time) and the demographic variables (age and sex of recipient), as well as the independent predictors of mortality previously identified from the backward stepwise analysis. The final multivariable model was also used to estimate the adjusted hazard ratio (aHR) for mortality during the first year post-HT for recipients with moderate or severe nutritional risk (NRI < 97.5) compared with recipients with mild or absent nutritional risk (NRI $\geq 97.5$ ).

Using a method similar to that described for the mortality analysis, we employed multivariable logistic regression to identify the predictors of postoperative adverse events for which the univariable analysis showed a statistically significant association $(P<.05)$ with the preoperative NRI values (postoperative infection and prolonged mechanical ventilatory support). Although the univariable analysis also showed a statistically significant association between preoperative NRI and incidence of postoperative stroke, we decided not to perform a multivariable analysis due to the low number of strokes recorded in the study population.

Lastly, the Kaplan-Meier method was used to construct survival curves for the first year post-HT for patients with moderate or severe nutritional risk (NRI < 97.5) and patients with mild or absent nutritional risk (NRI $\geq 97.5$ ). The 2 survival curves were compared using the logrank test. For all comparisons, a $P$-value $<.05$ was considered statistically significant. The statistical analysis was performed with SPSS 20.0 .

\section{RESULTS}

\section{Pretransplant Nutritional Risk}

From April 1991 to December 2014, 633 patients > 18 years old received an orthotopic HT in our center. The preoperative NRI could not be calculated in 89 (13\%) of them, because information on the pretransplant albumin levels was unavailable. Therefore, the sample analyzed consisted of 574 patients. 
Figure 1 shows the preoperative NRI distribution in the study population. Prior to HT, 33 patients $(5 \%)$ were at severe nutritional risk (NRI < 83.5); $146(22 \%)$ were at moderate nutritional risk $(83.5 \leq \mathrm{NRI}$ $<97.5)$, and $63(10 \%)$ were at mild nutritional risk $(97.5 \leq \mathrm{NRI}<100)$. The mean preoperative NRI was $100.9 \pm 9.9$.

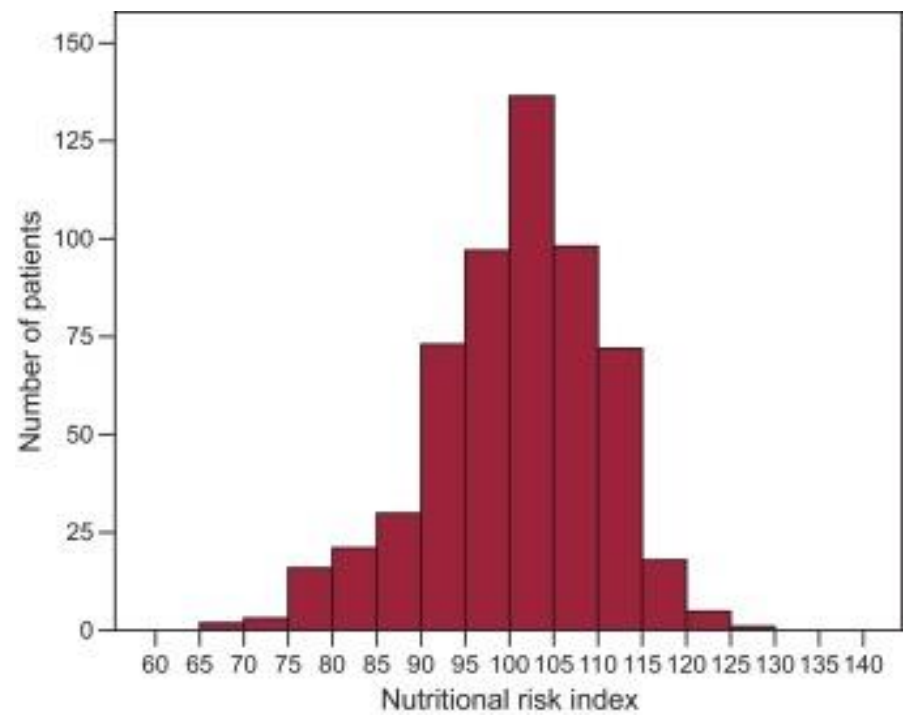

Figure 1. Distribution of preoperative nutritional risk index values in the study population.

Table 1 shows the baseline clinical characteristics of the study patients by the 4 nutritional risk categories described above. Life support measures, such as inotropes, mechanical ventilation, and mechanical circulatory support were used more frequently before HT in patients with a lower preoperative NRI and in cases of emergency HT $(P<.001$ for all linear contrasts of these variables). Patients with lower preoperative NRI were also younger $(P=.021)$ and had shorter waiting list times $(P$ $<.001)$, lower body mass index $(P=.001)$, lower serum albumin levels $(P=.004)$ and longer organ ischemia times $(P=.001)$.

Table 1. Clinical Characteristics of the Study Patients, by Pre-transplant Nutritional Risk

\begin{tabular}{|c|c|c|c|c|c|}
\hline & $\begin{array}{l}\text { Severe risk, } \\
\text { NRI < 83.5 } \\
(n=33)\end{array}$ & $\begin{array}{l}\text { Moderate risk, } \\
83.5 \leq \mathrm{NRI}<97.5 \\
(\mathrm{n}=146)\end{array}$ & $\begin{array}{l}\text { Mild risk, } \\
97.5 \leq \mathrm{NRI}<100 \\
(\mathrm{n}=63)\end{array}$ & $\begin{array}{l}\text { No risk, } \\
\text { NRI } \geq 100 \\
(\mathrm{n}=332)\end{array}$ & $\begin{array}{l}P \text { (linear } \\
\text { trend) }\end{array}$ \\
\hline Age, $y$ & $49.9 \pm 11.8$ & $54.1 \pm 11.3$ & $56.6 \pm 10.2$ & $\begin{array}{l}55.4 \pm \\
10.7\end{array}$ & .021 \\
\hline $\begin{array}{l}\text { Time on waiting } \\
\text { list, days }\end{array}$ & $26.5 \pm 50.1$ & $44.1 \pm 57$ & $92.5 \pm 100.2$ & $68.7 \pm 85$ & $<.001$ \\
\hline$N R I$ & $78.4 \pm 3.9$ & $92.1 \pm 3.7$ & $98.8 \pm 0.7$ & $\begin{array}{l}107.3 \pm \\
5.9\end{array}$ & $<.001$ \\
\hline Body mass index & $24.3 \pm 3.6$ & $25 \pm 4.3$ & $25.7 \pm 3$ & $26.7 \pm 4$ & .001 \\
\hline Women, \% & 15 & 22 & 18 & 15 & .119 \\
\hline $\begin{array}{l}\text { Underlying } \\
\text { heart disease, \% }\end{array}$ & & & & & .627 \\
\hline Ischemic & 61 & 34 & 45 & 43 & \\
\hline Dilated & 30 & 46 & 40 & 41 & \\
\hline Other & 9 & 20 & 25 & 16 & \\
\hline $\begin{array}{l}\text { Multi-organ } \\
\text { transplant, } \%\end{array}$ & 3 & 5 & 6 & 4 & .677 \\
\hline
\end{tabular}


Table 1. Clinical Characteristics of the Study Patients, by Pre-transplant Nutritional Risk

\begin{tabular}{|c|c|c|c|c|c|}
\hline & $\begin{array}{l}\text { Severe risk, } \\
\text { NRI }<83.5 \\
(n=33)\end{array}$ & $\begin{array}{l}\text { Moderate risk, } \\
83.5 \leq \mathrm{NRI}<97.5 \\
(\mathrm{n}=146)\end{array}$ & $\begin{array}{l}\text { Mild risk, } \\
97.5 \leq \mathrm{NRI}<100 \\
(\mathrm{n}=63)\end{array}$ & $\begin{array}{l}\text { No risk, } \\
\text { NRI } \geq 100 \\
(\mathrm{n}=332)\end{array}$ & $\begin{array}{l}P \text { (linear } \\
\text { trend) }\end{array}$ \\
\hline Retransplant, $\%$ & 0 & 3 & 7 & 1 & .193 \\
\hline $\begin{array}{l}\text { Emergency } \\
\text { transplant, } \%\end{array}$ & 85 & 36 & 21 & 11 & $<.001$ \\
\hline $\begin{array}{l}\text { Previous cardiac } \\
\text { surgery, } \%\end{array}$ & 24 & 21 & 27 & 26 & .349 \\
\hline $\begin{array}{l}\text { Diabetes } \\
\text { mellitus, \% }\end{array}$ & 18 & 14 & 28 & 15 & .732 \\
\hline $\begin{array}{l}\text { Recipient } \\
\text { seropositive for } \\
C M V, \%\end{array}$ & 91 & 80 & 86 & 84 & .854 \\
\hline Defibrillator, \% & 9 & 19 & 27 & 15 & .785 \\
\hline Inotropes, \% & 79 & 40 & 28 & 11 & $<.001$ \\
\hline $\begin{array}{l}\text { Mechanical } \\
\text { circulatory } \\
\text { support, \% }\end{array}$ & 70 & 29 & 16 & 7 & $<.001$ \\
\hline $\begin{array}{l}\text { Mechanical } \\
\text { ventilation, \% }\end{array}$ & 67 & 21 & 9 & 4 & $<.001$ \\
\hline Dialysis, \% & 0 & 4 & 2 & 1 & .108 \\
\hline $\begin{array}{l}\text { Creatinine, } \\
m g / d L\end{array}$ & $1.5 \pm 0.8$ & $1.5 \pm 1.4$ & $1.5 \pm 1.1$ & $1.4 \pm 1.2$ & .432 \\
\hline Bilirubin, $m g / d L$ & $1.3 \pm 0.8$ & $1.5 \pm 1.2$ & $1.3 \pm 0.7$ & $1.2 \pm 0.8$ & .004 \\
\hline Albumin, $m g / d L$ & $2.5 \pm 0.2$ & $3.4 \pm 0.3$ & $3.8 \pm 0.1$ & $4.3 \pm 0.4$ & $<.001$ \\
\hline $\begin{array}{l}\text { Pulmonary } \\
\text { vascular } \\
\text { resistance, } W U\end{array}$ & $1.9 \pm 1.2$ & $2.3 \pm 1.4$ & $2.2 \pm 1.2$ & $2.1 \pm 1.1$ & .083 \\
\hline $\begin{array}{l}\text { Mean pulmonary } \\
\text { pressure, mmHg }\end{array}$ & $32 \pm 11$ & $29 \pm 10$ & $30 \pm 11$ & $28 \pm 11$ & .204 \\
\hline $\begin{array}{l}\text { Female donor, } \\
\%\end{array}$ & 42 & 22 & 30 & 24 & .366 \\
\hline Donor age, $y$ & $39.1 \pm 5.6$ & $38.9 \pm 13.1$ & $40.2 \pm 13.6$ & $\begin{array}{l}37.4 \pm \\
13.8\end{array}$ & .209 \\
\hline $\begin{array}{l}\text { Ischemia time, } \\
\text { min }\end{array}$ & $219 \pm 81$ & $201 \pm 79$ & $202 \pm 82$ & $183 \pm 75$ & .001 \\
\hline ECC time, $\min$ & $126 \pm 20$ & $124 \pm 37$ & $128 \pm 46$ & $125 \pm 43$ & .990 \\
\hline
\end{tabular}

CMV, cytomegalovirus; ECC, extracorporeal circulation; NRI, nutritional risk index. Unless otherwise indicated, all values are expressed as mean \pm standard deviation. 
Table 2 summarizes the adverse clinical events that occurred during the in-hospital post-transplant period in the 4 patient subgroups defined by pretransplant NRI. Pretransplant NRI values had an inverse correlation with duration of postoperative vasoactive drug support $(P=.008)$, mechanical ventilation $(P<.001)$, and postoperative intensive care unit stay $(P<.001)$. Total postoperative hospital stay did not have a statistically significant association with preoperative NRI $(P=.332)$.

Table 2. Clinical Events in the In-hospital Post-transplant Period by Pretransplant Nutritional Risk Index

\begin{tabular}{|c|c|c|c|c|c|}
\hline & $\begin{array}{l}\text { Severe risk, } \\
\text { NRI }<83.5 \\
(n=33)\end{array}$ & $\begin{array}{l}\text { Moderate risk, } \\
83.5 \leq \mathrm{NRI}<97.5 \\
(\mathrm{n}=146)\end{array}$ & $\begin{array}{l}\text { Mild risk, } \\
97.5 \leq \mathrm{NRI}<100 \\
(\mathrm{n}=63)\end{array}$ & $\begin{array}{l}\text { No risk, } \\
\text { NRI } \geq 100 \\
(\mathrm{n}=332)\end{array}$ & $\begin{array}{l}p \text { (linear } \\
\text { trend) }\end{array}$ \\
\hline $\begin{array}{l}\text { Postoperative } \\
\text { ICU stay, days }\end{array}$ & $16 \pm 12$ & $10 \pm 11$ & $9 \pm 8$ & $7 \pm 12$ & $<.001$ \\
\hline $\begin{array}{l}\text { Total } \\
\text { postoperative } \\
\text { stay, days }\end{array}$ & $36 \pm 34$ & $26 \pm 27$ & $27 \pm 21$ & $25 \pm 45$ & .322 \\
\hline $\begin{array}{l}\text { Vasoactive } \\
\text { support, h }\end{array}$ & $97 \pm 83$ & $59 \pm 81$ & $53 \pm 98$ & $48 \pm 74$ & .008 \\
\hline $\begin{array}{l}\text { Mechanical } \\
\text { ventilation } \\
\text { duration, h }\end{array}$ & $176 \pm 168$ & $83 \pm 125$ & $70 \pm 115$ & $57 \pm 120$ & $<.001$ \\
\hline $\begin{array}{l}\text { Mechanical } \\
\text { ventilation }>36 \mathrm{~h}\end{array}$ & $24(73)$ & $62(43)$ & $21(33)$ & $80(25)$ & $<.001$ \\
\hline $\begin{array}{l}\text { Primary graft } \\
\text { dysfunction }\end{array}$ & $6(18)$ & $34(23)$ & $9(14)$ & $59(18)$ & .311 \\
\hline $\begin{array}{l}\text { Surgical } \\
\text { reintervention }\end{array}$ & $3(9)$ & $16(11)$ & $7(11)$ & $31(9)$ & .687 \\
\hline Acute rejection & $4(12)$ & $16(11)$ & $5(8)$ & $31(9)$ & .512 \\
\hline Infection & $13(39)$ & $40(27)$ & $16(25)$ & $59(18)$ & .001 \\
\hline Stroke & $2(6)$ & $4(3)$ & 0 & $3(1)$ & .022 \\
\hline Death & $6(18)$ & $37(25)$ & $5(8)$ & $34(10)$ & $<.001$ \\
\hline
\end{tabular}

ICU, intensive care unit; NRI, nutritional risk index.

Values are expressed as No. $(\%)$ or mean \pm standard deviation.

Univariable linear trend analysis revealed a statistically significant increased cumulative incidence in patients with lower preoperative NRI values of postoperative stroke (NRI $<83.5,6.1 \%$; $83.5 \leq \mathrm{NRI}<97.5$, $2.7 \% ; 97.5 \leq \mathrm{NRI}<100,0 \%$; NRI $\geq 100,0.9 \% ; P=.022)$, prolonged mechanical ventilatory support (NRI $<83.5,72.7 \%$; $83.5 \leq \mathrm{NRI}<97.5$, $43.1 \% ; 97.5 \leq \mathrm{NRI}<100,33.1 \%$; NRI $\geq 100,24.5 \% ; P<.001)$, and postoperative infection (NRI $<83.5,39.4 \%$; $83.5 \leq \mathrm{NRI}<97.5,27.4 \%$; $97.5 \leq \mathrm{NRI}<100,25.4 \%$; NRI $\geq 100,17.8 \%$; $P=.022)$. However, no statistically significant association was observed between preoperative NRI and the cumulative risk of other adverse events, such as primary graft dysfunction, cardiac surgical reintervention, or acute rejection during the post-HT hospital stay.

Multivariable logistic regression analysis identified preoperative NRI as a statistically significant independent predictor of prolonged need for postoperative mechanical ventilatory support (adjusted odds ratio [aOR] per unit $=0.96 ; 95 \%$ confidence interval $[95 \% \mathrm{CI}], 0.94-0.98 ; P=.001$ ) 
and postoperative infection (aOR per unit $=0.97 ; 95 \% \mathrm{CI}, 0.95-1.00 ; P=$ .027), as shown in Table 3. The statistical association between NRI and prolonged mechanical ventilatory support $(\mathrm{aOR}$ per unit $=0.96 ; 95 \% \mathrm{CI}$, $0.93-0.98 ; P<.001)$ and postoperative infection $(\mathrm{aOR}$ per unit $=0.98$; $95 \%$ CI, 0.95-1; $P=.038$ ) did not change substantially when the demographic variables (age and sex) and other clinical variables with asymmetrical distribution in the 4 nutritional risk categories (body mass index, bilirubin, mechanical ventilation, mechanical circulatory support, inotropes, and ischemia time) were forced into the regression model. 
Table 3. Independent Predictors of Prolonged Need for Ventilatory Support and Postoperative Infection Following Heart Transplant: Multivariable Analysis

\begin{tabular}{llc}
\hline & OR $(95 \% \mathrm{CI})$ & $P$ \\
\hline & & \\
Prolonged mechanical ventilatory support & & \\
Diabetes mellitus & $2.63(1.57-4.40)$ & $<.001$ \\
Pretransplant mechanical ventilation & $2.47(1.11-5.44)$ & $<.001$ \\
Pretransplant mechanical circulatory support & $4.71(2.41-9.21)$ & $<.001$ \\
Ischemia time (per 60 min) & $1.18(1.01-1.39)$ & .041 \\
Nutritional risk index (per unit) & $0.96(0.94-0.98)$ & .001 \\
Postoperative infection & & .050 \\
Diabetes mellitus & $1.66(1.00-2.67)$ & .014 \\
Pretransplant mechanical ventilation & $2.08(1.16-3.72)$ & .008 \\
Creatinine (per mg/dL) & $1.27(1.06-1.51)$ & .027 \\
Nutritional risk index (per unit) & $0.97(0.95-1.00)$ & \\
\hline
\end{tabular}

95\% CI, 95\% confidence interval; OR, odds ratio.

\section{Post-transplant Survival}

In the first year of follow-up post-HT, 102 patients $(17.8 \%)$ died. The in-hospital post-HT mortality rates were $18.2 \%, 25.3 \%, 7.9 \%$, and $10.2 \%$ $(P<.001)$ for recipients with severe, moderate, mild, and absent preoperative nutritional risk, respectively. In the same categories, the overall mortality rates in the first year after HT were $18.2 \%, 28.8 \%$, $11.1 \%$, and $14.2 \%(P<.002)$.

In the Cox multivariable regression analysis, preoperative NRI was identified as an independent predictor of lower risk of death from any cause in the first year post-HT (aHR per unit $=0.95 ; 95 \%$ CI, 0.93-0.98; $P$ $<.001)$ (Table 4). The statistical effect of preoperative NRI on mortality in the first year post-HT did not change substantially with the extended adjustment model that included demographic variables and baseline clinical variables with an asymmetrical distribution over the different nutritional risk groups $($ aHR per unit $=0.95 ; 95 \% \mathrm{CI}, 0.93-0.98 ; P=$ $.001)$.

Table 4. Independent Predictors of Mortality in the First Year Post-transplant: Multivariable Analysis

\begin{tabular}{lll}
\hline & HR (95\%CI) & $P$ \\
\hline & & \\
Diabetes mellitus & $2.11(1.28-3.48)$ & .004 \\
Previous cardiac surgery & $1.91(1.19-3.06)$ & .007 \\
Pulmonary vascular resistance (per WU) & $1.23(1.04-1.46)$ & .017 \\
Serum creatinine (per mg/dL) & $1.22(1.12-1.33)$ & $<.001$ \\
Nutritional risk index (per unit) & $0.95(0.93-0.98)$ & $<.001$ \\
& & \\
\hline
\end{tabular}


Patients with moderate or severe preoperative nutritional risk, defined as a preoperative NRI <97.5, had a significantly higher all-cause mortality in the first year post-HT than patients with mild or absent preoperative nutritional risk $(\mathrm{aHR}=1.55 ; 95 \% \mathrm{CI}, 1.22-1.97 ; P<.001)$ The Kapan-Meier survival curves for both groups are shown in Figure 2.

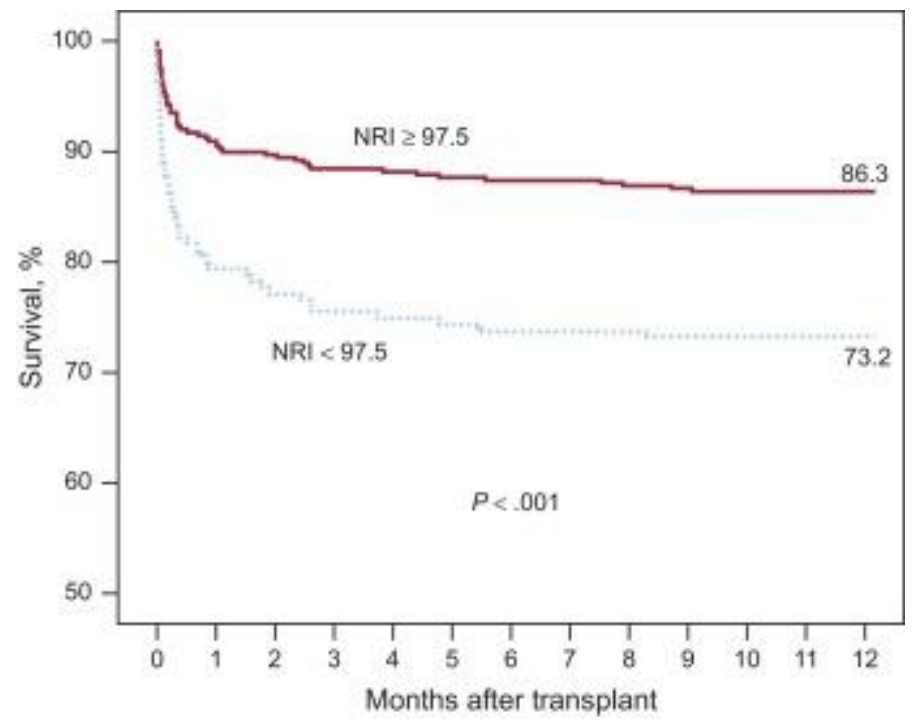

Figure 2. Survival curves for the first year post-transplant in patients with moderate or severe preoperative nutritional risk (NRI <97.5) and low or absent preoperative nutritional risk (NRI $\geq 97.5$ ). NRI, nutritional risk index.

\section{DISCUSSION}

In this cohort of 574 patients who received a HT in the A Coruña University Hospital Complex between 1991 and 2014, a statistically significant independent association was observed between lower preoperative NRI values and lower post-operative survival. Recipients with moderate or severe preoperative nutritional risk, defined as an NRI $<97.5$, had a $55 \%$ higher risk of death by any cause in the first year postHT than those with mild or absent nutritional risk. The incidence of postoperative complications such as stroke, prolonged mechanical ventilatory support, and infection was also significantly higher in malnourished patients.

Nutrition is a factor of growing importance in HF physiology. Several previous studies have demonstrated the usefulness of NRI in identifying $\mathrm{HF}$ patients at risk of malnutrition-related complications. In the HF population, a correlation has been found between lower NRI values and higher re-admission rates, longer hospital stays, and lower survival. ${ }^{7-10}$ The strong prognostic value of NRI appears to significantly exceed that of its 2 separate components, is independent of ejection fraction and other comorbidities, and is applicable to both inpatients and outpatients. In the specific setting of refractory HF, NRI can help in the process of selecting candidates for advanced therapies, as it provides increased prognostic value in addition to other validated risk scales. ${ }^{10}$ 
More than a third of HT recipients in our series were already at nutritional risk prior to surgery. Using the NRI cutoff points previously defined by other authors, ${ }^{7,9}$ the percentage of patients with severe, moderate, and mild preoperative nutritional risk was $5 \%, 22 \%$, and $10 \%$, respectively. This result is similar to those of previous studies, in which the prevalence of nutritional risk ranged from $23 \%$ to $48 \%$ in different HF patient populations, ${ }^{7-9}$ although we recognize that NRI is of limited use as an isolated criteria for the diagnosis of malnutrition. In our series, nutritional risk was higher in recipients in more critical clinical situations, such as those requiring inotropic support, mechanical ventilation, or mechanical circulatory assistance while awaiting HT. The association between NRI and mortality remained statistically significant after adjustment for multiple potential confounders, including body mass index. Thus, these results indicate that nutritional status has an independent effect on post-HT prognosis.

Malnourished patients are at higher risk of postoperative adverse events in various surgical situations, ${ }^{17}$ including major cardiac surgery. ${ }^{18}$ Malnutrition is a recognized cause of immunodeficiency, increasing the risk of postoperative infection through various pathophysiological mechanisms. ${ }^{19}$ In critical patients, malnutrition also predisposes to respiratory muscle dysfunction, making early weaning from mechanical ventilation difficult. ${ }^{20}$ Malnutrition-related complications frequently result in significant increases in postoperative hospital stay, health care costs, and mortality. ${ }^{17,18}$

Our study has direct implications for clinical practice. First, it confirms the usefulness of NRI as a simple and reliable tool for nutritional assessment in patients with advanced HF. The nutritional status of these patients has considerable prognostic implications and should therefore be closely-monitored, as is done with other risk markers such as functional capacity, hemodynamic status, or target organ function. Given the reduced life-expectancy ${ }^{10}$ in patients with $\mathrm{HF}$ and poor nutritional status, such patients should be assessed early to determine if they may be candidates for advanced therapies such as HT, provided there are no significant comorbidities. Our data also alert us to the lower survival rate after HT in individuals with marked nutritional impairment. Ultimately, serial determination of NRI could help identify HT candidates that could benefit from targeted nutritional interventions while awaiting transplant. ${ }^{21}$ For some of these patients, implantation of a long-term ventricular assist device could be a reasonable option, given the good outcomes in nutritional improvement that have been demonstrated with this therapy. ${ }^{22}$

\section{Limitations}

Our study has some methodological limitations. Given its retrospective design, it is subject to the potential selection bias and information bias inherent to this type of study. To control any potential confounding bias, rigorous multivariable adjustment was performed. Nonetheless, we cannot entirely rule out that another untested variable could have interfered with the observed statistical associations. The single-center setting of the study meant that the external validity of the results could not be guaranteed, therefore we may not be able to extrapolate our conclusions to other patient populations. The selection of a historic cohort spanning a long time period is in itself a limitation when interpreting the study results, which could have been affected by historic changes and improvements in the perioperative treatment protocol for HT patients. 
The lack of information on preoperative albumin levels led to the exclusion of 89 HT recipients from the study, but it seems unlikely that the inclusion of these patients in the analysis would have led to a significant change in the observed results. Lastly, as we retrospectively used previously-collected data, it is highly likely that the time elapsed from the preoperative determination of albumin level and body weight to HT varied between study patients.

\section{CONCLUSIONS}

Our study confirms the clinical usefulness of NRI as a screening tool for the nutritional status of patients with advanced HF who are candidates for HT. Malnourished recipients had a significantly higher incidence of post-HT complications such as infection, late weaning from invasive mechanical ventilation, and stroke, as well as longer postoperative intensive care stay, and lower survival. These results indicate the need for future studies to assess the potential clinical benefit of targeted interventions to improve the nutritional status of HT candidates. 


\section{Funding}

Several authors belong to the A Coruña Biomedical Research Institute Advanced Heart Failure and Heart Transplantation Research Group. This group regularly receives funding for the conduct of its scientific activities from the Instituto de Salud Carlos III (Carlos III Institute of Health) Cardiovascular Research Network, Ministry of Economics and Competitiveness, Government of Spain.

\section{Conflicts of interest}

None declared.

\section{Acknowledgements}

The authors would like to thank Zulaika Grille-Cancela, Paula BlancoCanosa, Cristina Costa-Graña, and Carmen Naya-Leira for their contribution to this study.

\section{References}

1. J.L. Bonilla-Palomas, A.L. Gámez-López, M.P. Anguita-Sánchez, et al.Impact of malnutrition on long-term mortality in hospitalized patients with heart failure

2. Rev Esp Cardiol., 64 (2011), pp. $752-758$

3. J. Parissis, D. Farmakis, N. Kadoglou, et al.Body mass index in acute heart failure: association with clinical profile, therapeutic management and inhospital outcome

4. Eur J Heart Fail., 18 (2016), pp. 298-305

5. T.B. Horwich, K. Kalantar-Zadeh, R.W. MacLellan, G.C. FonarowAlbumin levels predict survival in patients with systolic heart failure

6. Am Heart J., 155 (2008), pp. 883-889

7. P. Gastelarrubia, J. Lupón, M. Domingo, et al.Usefulness of body mass index to characterize nutritional status in patients with systolic heart failure

8. Am J Cardiol., 108 (2011), pp. 1166-1170

9. G.P. Buzby, L.S. Knox, L.O. Crosby, et al.Study protocol: a randomised clinical trial of total parenteral nutrition in malnourished surgical patients

10. Am J Clin Nutr., 47 (Suppl) (1988), pp. 366-381

11. O. Bouillanne, G. Morineau, C. Dupont, et al.Geriatric Nutritional Risk Index: a new index for evaluating at-risk elderly medical patients

12. Am J Clin Nutr., 82 (2005), pp. 777-783

13. Y. AL-Najjar, A.L. ClarkPredicting outcome in patients with left ventricular systolic chronic heart failure using a nutritional risk index

14. Am J Cardiol., 109 (2012), pp. 1315-1320

15. Y. Kinugasa, M. Kato, S. Sugihara, et al.Geriatric nutritional risk index predicts functional dependency and mortality in patients with heart failure with preserved ejection fraction

16. Circ J., 77 (2013), pp. 705-711

17. E.F. Aziz, F. Javed, B. Pratap, et al.Malnutrition as assessed by nutritional risk index is associated with worse outcome in patients admitted with acute decompensated heart failure: an ACAP-HF data analysis

18. Heart Int., 6 (2011), p. e2

19. O.L. Adejumo, T.M. Koelling, S.L. HummelNutritional Risk Index predicts mortality in hospitalized advanced heart failure patients

20. J Heart Lung Transplant., 34 (2015), pp. 1385-1389

21. M. Radman, R. Mack, J. Barnoya, et al.The effect of preoperative nutritional status on postoperative outcomes in children undergoing surgery for congenital heart defects in San Francisco (UCSF) and Guatemala City (UNICAR)

22. J Thorac Cardiovasc Surg., 147 (2014), pp. 442-450

23. T.S. Kato, F.H. Cheema, J. Yang, et al.Preoperative serum albumin levels predict postoperative 1-year survival in patients undergoing heart transplantation

24. Circ Heart Fail., 6 (2013), pp. 785-791 
25. M.J. Russo, K.N. Hong, R.R. Davies, et al.The effect of body mass index on survival following heart transplantation: do outcomes support consensus guidelines?

26. Ann Surg., 251 (2010), pp. 144-152

27. J. Kobashigawa, A. Zuckermann, P. Macdonald, et al., on behalf of the Consensus Conference participantsReport from a consensus conference on primary graft dysfunction after cardiac transplantation

28. J Heart Lung Transplant., 33 (2014), pp. 327-340

29. S. Stewart, G.L. Winters, M.C. Fishbein, et al.Revision of the 1990 working formulation for the standardization of nomenclature in the diagnosis of heart rejection

30. J Heart Lung Transplant., 24 (2005), pp. 1710-1720

31. G.J. Berry, M.M. Burke, C. Andersen, et al.The 2013 International Society for Heart and Lung Transplantation Working Formulation for the standardization of nomenclature in the pathologic diagnosis of antibody-mediated rejection in heart transplantation

32. J Heart Lung Transplant., 32 (2013), pp. 1147-1162

33. M.N. Thomas, J. Kufeldt, U. Kisser, et al.Effects of malnutrition on complication rates, length of hospital stay, and revenue in elective surgical patients in the G-DRG-system

34. Nutrition., 32 (2016), pp. 249-254

35 . H. Bayir, I. YildizMalnutrition and adverse effects in cardiac surgery

36. Thorac Cardiovasc Surg., 63 (2015), pp. 349-350

37. P. Katona, J. KatonaThe interaction between nutrition and infection

38. Clin Infect Dis., 46 (2008), pp. 1582-1588

39. L.M. Heunks, J.G. Van der HoevenClinical review: The ABC of weaning failure. A structured approach

40. Crit Care., 14 (2010), p. 245

41. E. Colin-Ramirez, L. Castillo-Martinez, A. Orea-Tejeda, V. RebollarGonzalez, R. Narvaez-David, E. Asensio-LafuenteEffects of a nutritional intervention on body composition, clinical status, and quality of life in patients with heart failure

42. Nutrition., 20 (2004), pp. 890-895

43. N. Dang, V. Topkara, B. Kim, B. Lee, R. Remoli, Y. NakaNutritional status in patients on left ventricular assist device support

44. J Thorac Cardiovasc Surg., 130 (2005), pp. e3-e4 